\title{
Between the Tides: Developing an Indigenous-Informed Cultural Safety Training Impact Assessment Survey Tool for Post-Secondary Institutions on Vancouver Island, BC
}

\author{
Paul Whitinui \\ University of Victoria \\ whitinui@uvic.ca \\ Skip Dick \\ University of Victoria \\ lindadick2@gmail.com \\ Billie Alan \\ University of Victoria \\ allanb@uvic.ca \\ Charlotte Loppie \\ University of Victoria \\ loppie@uvic.ca \\ Tara Erb \\ University of Victoria \\ taralise@uvic.ca \\ Rob Hancock \\ University of Victoria \\ rola@uvic.ca \\ Rebecca Duerksen \\ University of Victoria \\ rebeccamduerksen@gmail.com \\ Cortney Baldwin \\ University of Victoria \\ cortneybaldwin@uvic.ca
}




\begin{abstract}
This paper highlights the development of an Indigenous Cultural Safety Training (ICST) impact assessment survey tool working in collaboration with Indigenous leaders, Elders, faculty, staff, and students from across four post-secondary institutions on the traditional lands of the Songhees, Esquimalt and WSÁNEĆ Peoples on Vancouver Island, British Columbia. What emerged from a series of Indigenous-led workshops was the development of an ICST impact assessment survey tool to measure the impact of the training as well as for ICST participants to reflect on their own cognitive and behavioural change within their practice over a 12-month period. In addition, a validation process with ICST experts, facilitators, staff, faculty, Elders, and participants was carried out to help refine the proposed co-constructed assessment variables, statements, and questions underpinning the survey tool. The finalized ICST impact assessment survey tool will not only improve the quality of ICST in post-secondary settings, but will also enable staff, faculty, and leaders to reflect on how the ICST improves their personal and professional practice working with Indigenous students in these settings.
\end{abstract}

\title{
Introduction
}

Even as the number of Indigenous students enrolling at Canadian universities increases, the representation of Indigenous staff, faculty, and leaders within these institutions remains disproportionately less than the number of non-Indigenous students, staff, faculty, and leaders (Universities Canada, 2015). More recently, increasing the visibility and representation of Indigenous Peoples in post-secondary institutions has depended on leaders prioritising and committing to equity, diversity, inclusion, and decolonizing strategies that validate and expand Indigenous ways of knowing in these settings (Gerlach, 2012; MacIntyre, 2016). Across Canada, many post-secondary institutions are working to develop and enhance the capacity of their staff, faculty, administrators, and student leaders to be more culturally safe, with a focus on identifying unconscious biases that perpetuate racist attitudes and behaviours. This work attempts to address the many challenges highlighted within the Truth and Reconciliation Commission's (TRC) Calls to Action (2015) encouraging professionals in health (Calls to Action 23 \& 24, p. 3), law (Calls to Action $27 \&$ 28, p. 3), business (Calls to Action 92, p. 10), education (Calls to Action 10.i.vii., p. 2), and the public sector (Calls to Action 57, p. 7) to design and implement programming that ensures emerging professionals understand the diverse contexts influencing the lives of Indigenous Peoples. In addition, these programs respond to what is highlighted in the TRC as a need for "skills-based training in intercultural competency, conflict resolution, human rights, and anti-racism" (Calls to Action 92.iii., p. 10).

Despite a recognized need for and growing interest in developing cultural safety training programs in the workplace, there remains a dearth of studies that adequately assess their impact (Javidan \& House, 2001; Kirkham et al., 2002). A review of literature reveals that evaluations of the overall quality of cultural safety training (i.e., specific skills that translate to an individual's and/or organization's practice), and therefore how cultural safety practice translates to sustainable change over time (Lenette, 2014, p. 118), are significantly under-developed (BrooksCleator et al., 2018). A range of approaches are used to deliver cultural safety training programs; however, very few programs have addressed how best to evaluate the impact of cultural safety 
training specific to their own institutions or organization.

The following article details the early stages of conceptualizing and developing an Indigenous cultural safety training impact assessment survey tool designed to help facilitators of Indigenous Cultural Safety Training (ICST) better assess the long-term impact and efficacy of the training in post-secondary settings. This Indigenous-led project was funded by a 3-year Social Sciences and Humanities Research Grant and involved the voluntary participation and collaboration of Indigenous Elders, leaders, staff, faculty, and students from four post-secondary institutions on Vancouver Island, including the University of Victoria, Vancouver Island University, Royal Roads University, and Camosun College. What these four schools currently offer in terms of cultural safety training varies in the number of hours and required time commitment of each program, as well as in specific topics covered and methods of instruction. Despite differences in implementation and approach, these programs are designed to ensure Indigenous students, staff, faculty, and leaders feel safe, seen, and adequately supported within post-secondary teaching and learning environments. The impact assessment survey tool created through this project will be specific to the institutions that played a role in its development and will support facilitators in identifying areas of training that can be improved and strengthened. We begin this paper by outlining some core concepts and key theories that informed our methodological approach for conducting this collaborative and Indigenous-led research. Next, we share a detailed summary of the preliminary findings that emerged from the initial full and half-day workshops conducted with Indigenous students, leaders, faculty, and staff from the 4 participating post-secondary institutions. Lastly, we touch briefly on "next steps" and how we intend to move forward with the information, stories, and insights collected from participants and key collaborators on this project, including how we plan to validate the study's findings and finalize the survey tool.

\section{Methodology}

\section{Conceptualising ICST variables in post-secondary settings}

To assess the impact of ICST, it is important to understand what is meant by cultural safety training. The term "cultural safety" emerged in the late 1980s in the context of creating culturally appropriate programs for Māori in the nursing and health sector in Aotearoa New Zealand (Ramsden \& Spoonley, 1994). Cultural safety requires service providers to consider the social and historical contexts of their interactions with service users and aims to raise self-awareness around issues of positionality, power, and privilege, including their implications for how safe or satisfied service users feel in their interactions with service providers (Churchill et al., 2017). In a Canadian context, cultural safety initiatives such as the B.C. Provincial Health Services Authority San'yas Cultural Safety Training are often aimed at critically unpacking ideas associated with white(ness) privilege, power, and racism (J. Anderson et al., 2003; Ball, 2009; Provincial Health Services Authority, 2016) and the stereotypical views that accompany unconscious bias and racist behaviours (Loppie \& Wien, 2009; Reading, 2013). Culturally unsafe practices may reflect what Curtis and colleagues (2019) identify as a narrow understanding of the differences between cultural competency, which often focusses on individualized cultural knowledge, and the reflective self-assessment of power and privilege inherent within the structure of organizations and institutions. In this regard, cultural safety training is not about acquiring a set of prescribed competency skills but rather asks professionals and organizations to critically examine potentially harmful attitudes and assumptions of Journal of Contemporary Issues in Education, 2021, 16(2), pp. 55-83. 
individuals, structures, and systems that are likely to perpetuate biases, stereotypes, and prejudices that can negatively impact Indigenous Peoples' health and wellbeing (Curtis et al., 2019). Since the 1990s, cultural safety training has been employed across a variety of professional settings - including post-secondary institutions - as part of an effort to address the gross inequalities many Indigenous Peoples continue to face today (Boyce, 2016; Public Health Agency of Canada, 2018).

Cultural safety training is anti-colonial in nature and attempts to dismantle various forms of racial discrimination towards Indigenous Peoples in all areas of society. As such, culturally safe and/or trauma informed curriculum must consider the deep physical and psychological impacts that colonial policies and practices continue to have on the lives of Indigenous Peoples (and other marginalized groups). Moreover, they must refrain from blaming or merely seeing Indigenous Peoples as problems that needs to be fixed or as victims of current social-political plight (Ramsden, 1990, 2002; Ramsden \& Spoonley, 1994). Considering cultural safety training as an educational imperative involves sharing information about Indigenous Peoples' social, political, and historical struggles in order to contextualize the responsibility of institutional leaders to redress unequal power relations that continue to marginalize and oppress Indigenous Peoples (Health Council of Canada, 2012; Anderson et al., 2003; Ramsden \& Spoonley, 1994). In this regard, our work reflects the understanding of the interconnections between prevalent racialized attitudes, beliefs, and behaviours at systemic, structural, and interpersonal levels.

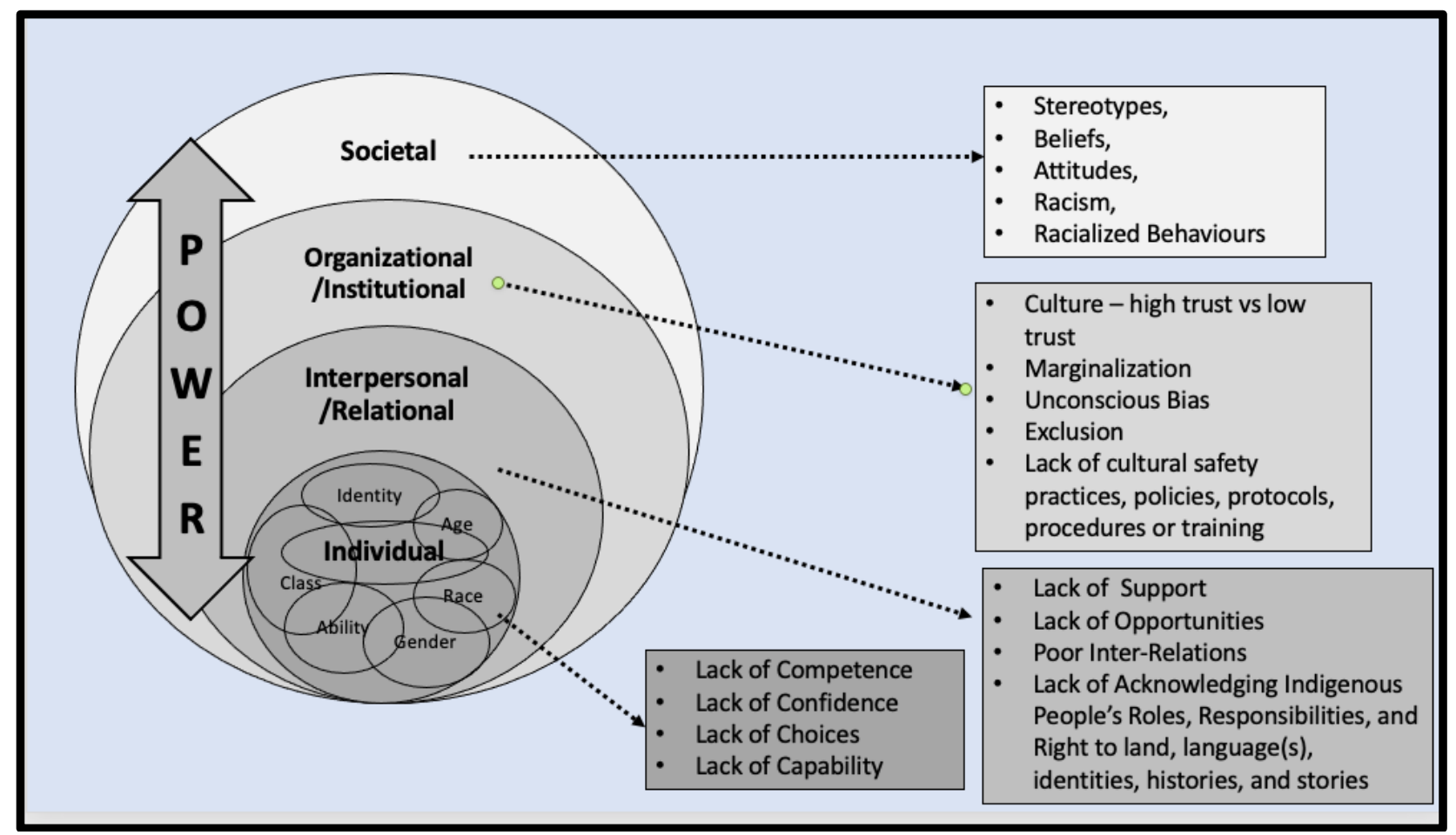

Figure 2: Key Elements of Culturally Unsafe Practices

ICST is understood as a cultural learning modality that is not only heavily dependent on the instructor and the institutions who delineate the parameters of the training curriculum (Erb, 
2020) but also on the openness and willingness of participants to address their own levels of racial bias. As such, developing a tool to better manage, measure, and report on the impact of ICST is essential not only in caring for Indigenous post-secondary students in culturally safe ways, but also for ICST facilitators who recognize the importance of reflecting on and improving the quality and effectiveness of their delivery of ICST programs over time. The following section will address the converging and relational nature of the research design we developed for this project.

\section{Convergent research design}

A convergent research design is one that considers both Indigenous and western ways of knowing (Figure 3). Privileging Indigenous ways of knowing enabled the project to draw on relational ways of knowing from within our group of researchers and collaborators whilst adhering to the cultural protocols, practices, and principles of the Songhees, Esquimalt and WSÁNEĆ peoples, and with cultural support and guidance from a Songhees Elder, Dr. Skip Dick.

\section{Researchers, collaborators and participants}

In the spirit of community-engaged research, the project invited a number of Indigenous institutional leaders, Elders, staff, students, and faculty to come together to discuss the benefits of developing an impact assessment tool to better assess the impact of ICST training. The project was hosted by the University of Victoria and conducted on the traditional territory of the Songhees, Esquimalt and WSÁNEĆ peoples whose relatonships with the land continue to this day. Here within is a brief list of everyone involved on the project and their various roles:

- Dr. Paul Whitinui (Ngā Puhi, Te Aupōuri, Ngāti Kurī, Pākehā - NZ Māori) is a professor in the School of Exercise Science, Physical and Health Education at the University of Victoria and the principal investigator on this project. As an interdisciplinary social scientists and educator, his interests include improving Indigenous student participation and success levels in post-secondary institutions, culturally responsive, safe and inclusive pedagogies, decolonization, anti-racism, and Treatyrelational understandings that benefit Indigenous Peoples in educational settings.

- Dr. Billie Allan (Anishinaabe) is an assistant professor in the School of Social Work at the University of Victoria and is a co-principal investigator in this project. Dr. Allan was instrumental in the planning and facilitation of the sharing circle ICST workshops across all four post-secondary institutors on Vancouver Island using Anishinaabe cultural protocols and practices. Dr. Allan is also a leading Indigenous scholar working in the areas of Indigenous health and wellbeing (particularly related to Indigenous women's and Two-Spirit health, anti-racism, and health and healing in the context of child welfare).

- Dr. Rob Hancock (Cree-Metis-English) is an assistant professor in anthropology and history, as well as the Associate Director for the Office of Indigenous Academic and Community Engagement (IACE) at the University Victoria. As a co-principal investigator, Dr. Hancock helped to shape the ICST impact assessment items, categories, variables, statements, and questions underpinning the ICST impact assessment survey 
tool. He is also a faciliator of the Indigenous cultural acumen training for all staff, students, and faculty based at the University of Victoria. Once the ICST impact assessment survey tool has been finalized, Dr. Hancock has offered to support the running of a 3-month pilot using the tool.

- Dr. Charlotte Loppie (Mi'kmaq, Acadian) is a professor in the School of Public Health and Social Policy at the University of Victoria and a co-principal investigator on the project. Dr. Loppie played a significant leadership role in the development of the project proposal and was instrumental in analysing and categorizing the key themes underpinning the development of the ICST impact assessment survey tool.

- Dr. Skip Dick (Elder, Songhees First Nations) has a long-standing relationship with the University of Victoria. Dr. Dick also helped to oversee all the ICST workshops and meetings. This involved welcoming visitors to the territory and speaking about the importance of culturally safe schooling and education for all Indigenous students to be successful.

- Dr. Qwul'sih'yah'maht Robina Thomas (Lyackson First Nation) is the VP Indigenous at the University of Victoria and a collaborator on the project. Dr. Thomas also helps to lead and facilitate the delivery of cultural acumen training at the University of Victoria.

- Dr. Sharon Hobenshield (Gitxsan First Nations) is the Director of Aboriginal Education at Vancouver Island University and a collaborator on the project. Dr. Hobenshield also helps to lead and facilitate the delivery of cultural safety training opportunities at Vancouver Island University.

- Asma-na-hi Antoine (Toquaht, Nuu-chah-nulth) is the Manager of Indigenous Education and Student Services at Royal Roads University and a collaborator on the project. Asma also helps to lead and facilitate the delivery of cultural safety training at Royal Rhodes University in Victoria, BC. Once the ICST impact assessment survey tool has been finalized, Ms. Antonie has offered to support the running of a 3-month pilot using the tool.

- Dr. Todd Ormiston (Northern Tutchone/Tlingit) is the Chair of Indigenous Studies based at Camosun College (Lansdowne Campus) in Victoria, BC, and a collaborator on the project. Todd also helps to lead and facilitate the delivery of cultural safety training at Camosun College.

- Dr. Ryan Rhodes is a professor in the School of Exercise Science, Physical and Health Education (EPHE) at the University of Victoria. Dr. Rhodes' work related to the intention-behaviour gap model helped to inform the cognitive (mental) and affective (emotional) variables, statements, and questions underpinning the survey tool. The intention-behaviour gap model was influential in helping us to better understand the motivations attributed to one's actions and behaviours related to individuals choosing to be culturally safe or unsafe. 
- Dr. Onowa McIvor (Swampy Cree) is a professor in Indigenous Education at the University of Victoria. Dr. McIvor is an expert in the area of Indigenous Language Revitalization and has worked to develop a language learning assessment tool that assesses the proficiency of Indigenous language learners. Dr. McIvor's insights and feedback were instrumental in the intial development, validation, and finalization of the ICST impact assessment tool.

- Cortney Baldwin is the project manager responsible for organizing the ICST workshops and follow-up meetings. Cortney also assisted in the drafting and submitting of the ethics application for this project and created the on-line ICST impact assessment survey tool for this project.

- Rebecca Duerksen is a research assistant responsible for helping to plan and organize the validation workshops that enabled us to further refine the ICST impact assessment survey tool. She also worked to develop a "Companion Guide" that outlines key components of the Impact Assessment Framework and instructs ICST facilitators on how to use the ICST impact assessment survey tool.

- Tara Erb (Moose Cree) is a research assistant on the project and was responsible for organizing the initial ICST workshops with collaborators. Tara also helped to conduct a comprehensive literature review for the project and assisted in collating and analysing the feedback from the workshops using the qualitative computer analysis software program, NVivo.

- Dr. Manjinder Cheema is a Senior Research Associate working in Medical Sciences at the University of Victoria. Dr. Cheema is a data analysis expert who is helping to import, organize, and interpret the data from the survey to determine whether or not the training is working and to address areas within the training that can be further improved or developed.

Indigenous students, staff, faculty, facilitators of ICST, and Elders from across all four postsecondary institutions on Vancouver Island were invited to attend the half-day workshops. The numbers who chose to attend each workshop varied between 5-15. Given the conceptual nature and scope of the project, it made sense to not only illicit feedback from those who facilitate or who are responsible for developing the ICST, but also from those who had experienced culturally unsafe situations, interactions, or encounters in post-secondary settings. Although the majority of people who attended were Indigenous, we did have few non-Indigenous staff and faculty interested in learning more about the project as it relates to their own roles working in these settings. As Torchiano and colleagues (2017) explain,

when designing a survey, the main question is which should be its target population? The choice of the target population is crucial. The decision to include gender, age, position, department, role and years working in an institution was strategic in helping the survey to report more specifically on the impact of the training for various groups at various stages 
of their time working within an institution. The adequacy of respondents to provide significant answers decides upon the success of the survey. (p. 35)

Therefore, the information we opted for in the development of the survey tool privileged the opinions, expectations, and experiences of Indigenous respondents as it pertains to their own unique environments (Torchiano et al., 2017). Macfarlane, Blampied, and Macfarlane (2011, p. 11) refer to such interactions as working to develop a culturally reasoned epistemology that is rooted in both clinical and social-cultural approaches. In this regard, the project was underpinned by the following four theories.

\section{Theorizing Indigenous-Settler Relations in Collaborative Research}

\section{Culturally-responsive theory}

Cultural responsiveness is the ability to learn from and relate respectfully with people of your own culture as well as those from other cultures. (NCCRESt, 2008, p. 40)

Culturally-responsive theory recognizes the importance of including cultural references in all aspects of learning (Ladson-Billings, 2009) and supports individuals to better assess their own levels of cultural responsiveness, proficiency, or competency in specific educational settings and contexts (Cross et al., 1989). Sasakamoose and colleagues (2017) argue, however, that establishing a "middle ground" by remaining open, willing, and respectful of difference is important, not only for how people acquire new knowledge but also for how they understand and apply it. For our purposes, a culturally-responsive approach was developed to ensure that the guidelines, processes, and outcomes of this project maintained and valued relationships over and above the goals of the project. The collaborative nature of the project created a "converging middle ground," where both Indigenous and non-Indigenous (i.e. behaviour change theory) ways of knowing were valued and included. In addition, the (w)holistic (Absolon, 2011) process of achieving a "converging middle ground" opened up spaces for dialogue to happen more fluidly, organically, and respectfully. 


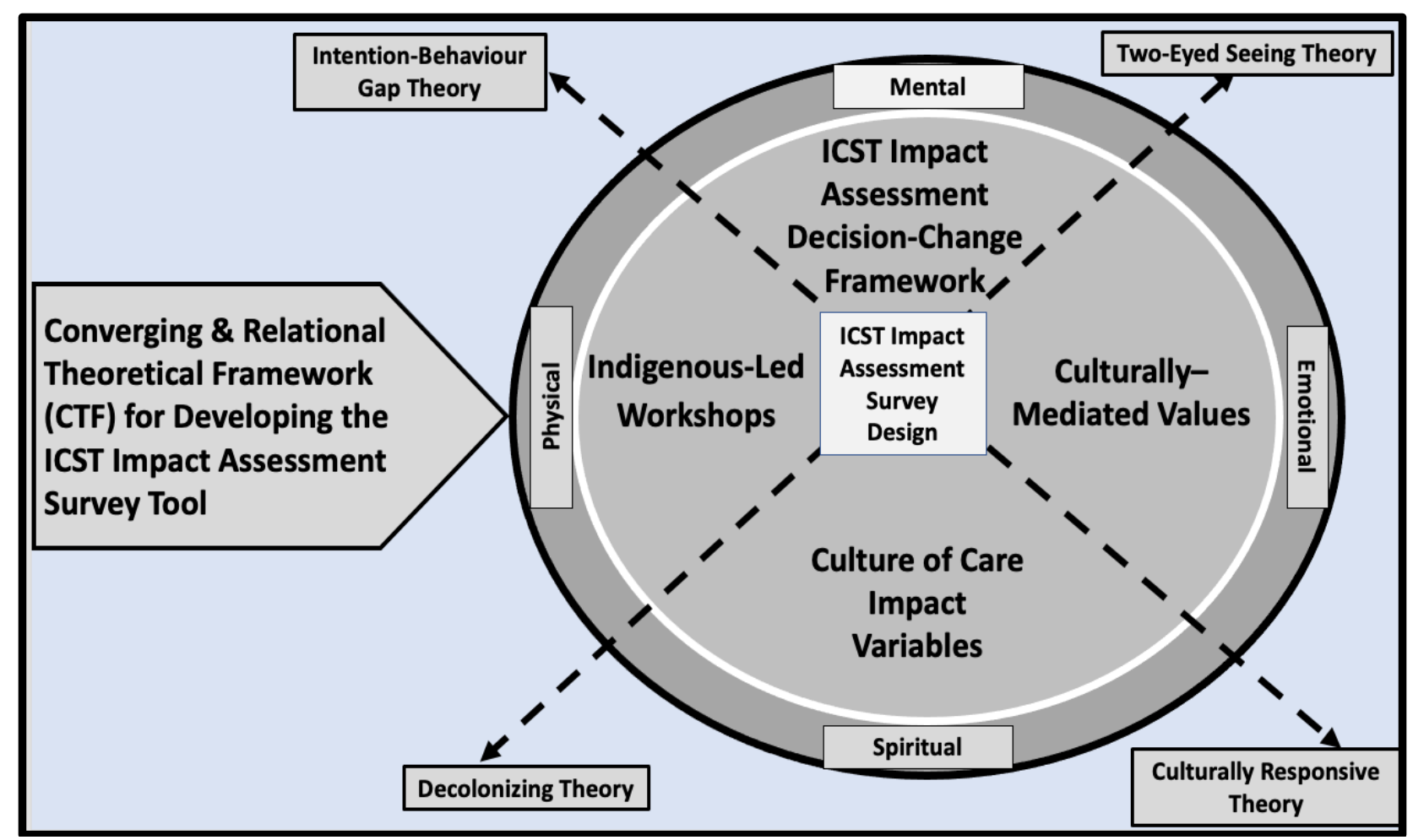

Figure 3: Converging and Relational Theoretical Framework to Inform the Development of an ICST Impact Assessment Tool

\section{Decolonizing theory}

Decolonization offers a different perspective to human and civil rights-based approaches to justice, an unsettling one, rather than a complementary one. Decolonization is not an "and." It is an "elsewhere." (Tuck and Yang, 2012, p. 36)

Decolonization can be defined as the tools, processes, and lived experiences of identifying, evaluating, rethinking, and intentionally changing parts of ourselves and society where privileged and oppressed identities hinder our progress toward an inclusive, sustainable, and relational way of being (Datta, 2017; L. T. Smith, 2012). Monocultural colonial practices disguised within a pseudo-multicultural ideology still remain the dominant discourse that informs health and educational policy, practices, programs, and processes in Canada. We employed decolonizing theory to reinforce the necessity of ICST objectives to create culturallysafer (decolonized and anti-racist) spaces. Developing an effective and useful ICST assessment survey tool requires both a decolonizing process and a decision- and change-making framework to ensure the assessment is not steeped in a colonial ideology that reinforces the status quo or that fails to challenge unjust and unsafe practices and social disparities based on power imbalances seeded and maintained by colonialism. 


\section{Two-Eyed Seeing theory}

Only when we see with two eyes, will Western science be something more than blind and Aboriginal thought something more than lost. (Mi'kmaw Elder Albert Marshall, qtd. in Marshall, 2015, slide 19)

Two-Eyed Seeing honours Indigenous as well as western approaches to conducting research in a just and equitable way (Marshall \& Bartlett, 2010; Marshall et al., 2015). Saskamoose and colleagues (2017) quote Marshall's description of Two-Eyed Seeing as the ability "to see from one eye with the strengths of Indigenous knowledges and ways of knowing and from the other eye with the strengths of western knowledges and ways of knowing and to use both of these eyes together" (p. 8). Moreover, the uptake of Two-Eyed Seeing as a socio-historical-political approach to conducting research by Indigenous scholars such as Marie Battiste (transsystemic knowledge), Dwyane Donald (ethical relationality), Martin Nakata (the cultural interface), and Willie Ermine (ethical space) demonstrates how knowledge(s) can converge, co-exist, and coalesce to address similar issues, problems, and challenges in innovative and creative ways (Battiste, 2004; Donald, 2016; Ermine, 2007; Nakata, 2002).

\section{Intention-behavior gap theory}

Your beliefs don't make you a better person, your behavior does (Dhillon, 2010)

In assessing the impact and quality of ICST, it was necessary to adopt a model that could effectively measure and report on levels of empathy, an important component of cultural safety. The processes associated with the cognitive domain relate to intention formation, beliefs, and attitudes, and include empathy, goal setting, personal judgment, self-regulation, and application (Warren \& Weatherford, 2013). Rhodes and Yao's (2015) intention-behaviour gap model considers how various cognitive and affective attributes, aspects, and actions motivate people to choose whether or not to be physically active, according to the rationale that how people think and/or feel is linked to choices specific to whether or not individuals have the opportunities and resources to access being physically active. In addressing choices impacted by power relations in white sumpremist colonial systems, there requires what Graham Hingangaroa Smith (2014) refers to as both a horizontal (policy and leadership) and a vertical (curriculum, environment, and interpersonal) shift that are committed to work-related equity, inclusion, diversity, and decolonization. Vertical shifts can not be sustained without horizontal shifts geared towards social-political change (G. H. Smith, 2014). In the context of ICST, we apply the intentionbehaviour gap theory to understand the relationship between an individual's stated intention and their subsequent behaviour.

Another important consideration is context, including how existing hegemonic power or ruling relations within an existing organization or structure can shape individuals' opinions or influence how individuals reflect and revise their existing beliefs and change their behaviour(s) - for better or worse (Moussaïd et al., 2013; D. E. Smith, 2005). The intention-behavior gap theory will help us to examine more closely participants' motivations for participating in cultural safety training and how we might improve the delivery and the content of the training itself. The culmination of 
these theoretical approaches also provided the impetus for adopting a culturally reasoned, inclusive, and convergent theoretical framework that uses methods designed by us, for us.

\section{Methods}

\section{Survey design}

Our work to develop a tool to measure and report the impacts of ICST in post-secondary settings was founded on what an Elder from Songhees Nation, Dr. Skip Dick, referred to as "Being (or Becoming) a Good Relative" (personal communication, April $1^{\text {st }}, 2019$ ). From this perspective, the art of being a culturally safe teacher has been defined as someone who is consistently reflecting on ways to be in "Good Relations." Moreover, "Being a Good Relative" requires staff, faculty, and leaders to build positive relationships for teaching and learning that respect Indigenous students' identities, histories, pride, and self-worth (Environics Institute, 2010). As part of creating a converging and relational theoretical framework, it was important to also identify what constitutes culturally unsafe spaces (Ball, 2009; Ball et al., 2013; Reading, 2013) (see Figure 2 and Figure 4). What followed was a number of Indigenous-led workshops that proposed a range of culturally-explicit items, categories, variables, statements, and questions to help inform the development of the impact assessment survey tool.

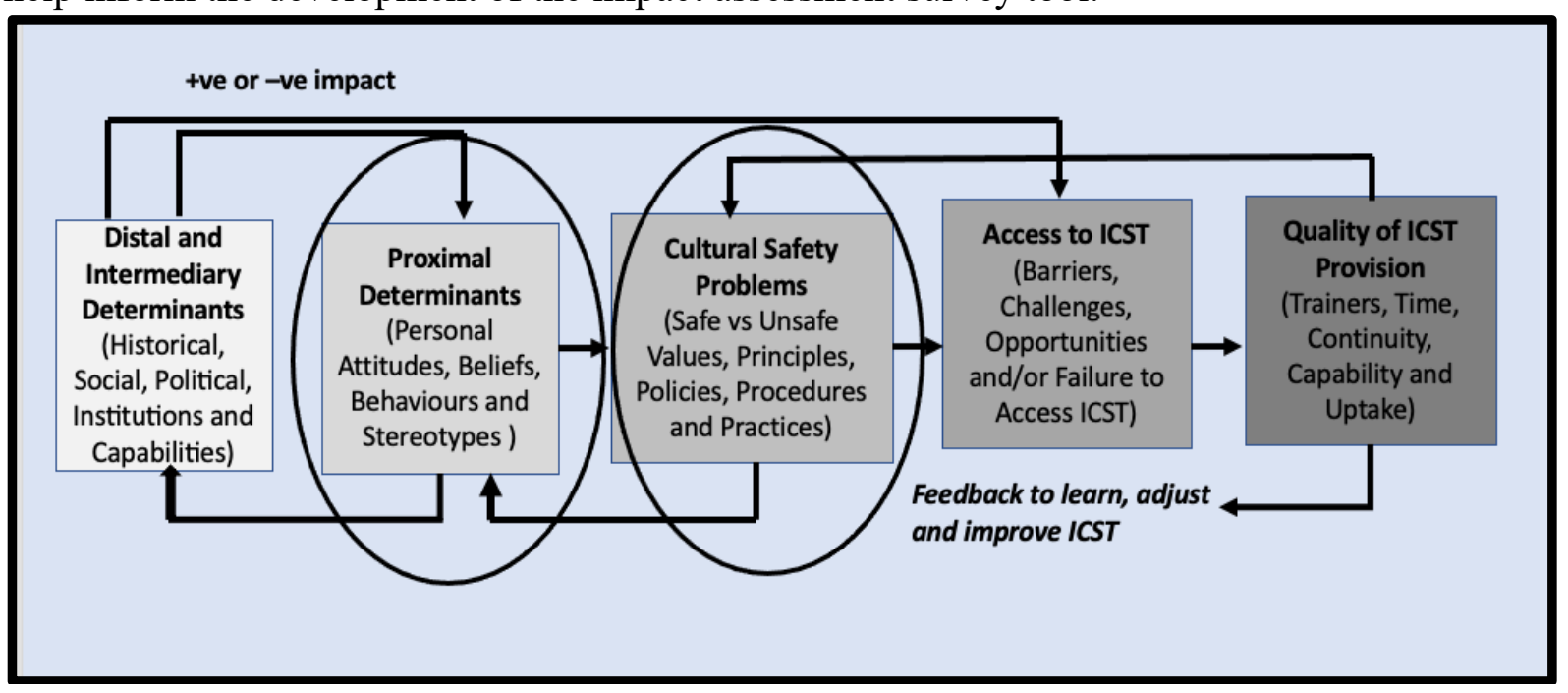

Figure 4: Culturally Safety Decision and Change Making Framework

\section{Indigenous-led workshops}

The half-day workshops were conducted individually in each of the four post-secondary institutions on Vancouver Island, BC: University of Victoria, Royal Rhodes University, Vancouver lsland University, and Camosun College. The workshops utilized a sharing circle methodology (Thomas \& Green, 2007) that included Songhees, Esquimalt, and WSÁNEĆ First Nations' cultural protocols, and they were led by an Anishinaabe woman, Dr. Billie Alan, who is a faculty member based in the Department of Social Work at the University of Victoria, BC. A group of Indigenous leaders, Elders, students, staff, and faculty from each post-secondary institution were invited to discuss a series of questions relating to the perceived purpose and intent of ICST within their institutions. A sharing circle, alongside the appropriate protocols, 
enabled everyone to see and hear what was being said in mutually respectful ways. Utilising a sharing circle methodology is also about acknowledging and respecting the essence of everyone present. This involved creating space and time prior to the start of the workshops where everyone in attendance were able to visit with each other and share food (Baskin, 2005, p. 179). The majority of participants who attended identified as Indigenous, many of whom held extensive knowledge and experience working with Indigenous students in such settings. Indigenous Elders who attended the workshops provided a level of cultural safety by conducting cultural protocol (prayer, history of the lands, words of encouragement, and teachings). As a result, participants felt welcomed, comfortable, and safe discussing their roles in relation to the ICST, and how they thought the training could be improved. Four key questions helped to frame and guide the discussions at each of the workshops:

1. How would you describe the role and importance of cultural safety training in your institution?

2. (i) How would you know if the cultural training was effective or not?

(ii) How would participants demonstrate their learning with their words and actions?

3. What questions would you ask participants who have completed cultural safety training to assess their learning and growth?

4. Is there anything we haven't asked about today that you would like to share to help inform our work to develop a survey to assess the impact of cultural training on participants?

\section{Initial Findings}

Feedback from the half-day workshops was collated, managed, and stored using a qualitative data management system called NVivo 11. Through a close reading of the insights, stories, and experiences shared by participants, the following five themes emerged.

\section{The purpose of Indigenous cultural safety training}

The first theme relates to the purpose of ICST. According to participants, ICST is intended to address racism, protect students, and contribute to reconciliation.

\section{Addressing racism}

Participants suggested that ICST plays a major role in addressing epistemic, systemic, and interpersonal racism and resulting harms. Foundational to this is an acknowledgment that western education is grounded in racist beliefs about Indigenous peoples and that students' learning is often limited to the burdens and challenges (e.g., health, economic, social) facing Indigenous communities, with little to highlight the aspirations, strengths, and gifts of Indigenous peoples and cultures. ICST foregrounds white privilege and helps participants appreciate that this privilege is unearned and comes at the expense of Indigenous and other racially marginalized peoples. ICST also encourages those who live with white privilege to accept their responsibility to contribute to the dismantling of systems that unfairly advantage them in education, employment, housing, etc. Participants stressed that ICST inspires nonIndigenous Peoples to "step up" and walk with Indigenous people in the struggle against racism. Notably, ICST is meant to instill a sense of responsibility to understand one's impact on others, without overtly teaching participants how to do things differently. 


\section{Protecting students}

Participants emphasized the critical role ICST plays in creating safe and inclusive spaces for Indigenous students. They maintained that culturally-safe instructors create culturally-safe classrooms, where Indigenous students feel safe to participate in discussions without fear of racist or demeaning comments. In better preparing instructors about both white privilege and racism and about Indigenous histories and contexts, the burden is lifted off of Indigenous students to educate their classmates and sometimes their instructors. Moreover, with a culturallysafe instructor, Indigenous students feel confident that, if racist remarks are made by classmates, the instructor will address them appropriately.

\section{Contributing to reconciliation}

According to participants, ICST is a key feature of reconciliation. In particular, enabling nonIndigenous people to recognize the social, political, and economic inequities experienced by Indigenous Peoples is a primary function of ICST. In discussions about the role of ICST in reconciliation, participants specifically referred to both the TRC's 94 Calls to Action (2015), the United Nations Declaration on the Rights of Indigenous Peoples (UNDRIP) (United Nations General Assembly, 2007) as well as the First Peoples Principles of Learning (First Nations Education Steering Committee, 2014). They also emphasized the relational dimensions of ICST in its capacity to create safe spaces for dialogue about difficult issues and spaces of truth, where everyone's voice is valued. It is significant that participants described culturally-safe spaces as places of humility, acceptance, and compassion, where balanced relationships between human beings are restored.

\section{The process of Indigenous cultural safety training}

The next theme relates to the process or "how" of ICST, which participants described as involving specific strategies and techniques used by ICST facilitators. Workshop participants who were engaged as ICST facilitators shared a number of strategies they employed in order to fully engage ICST participants and enhance the impact of training. A key feature of ICST is the creation of spaces where participants feel respected and engaged. In fact, facilitators emphasized that people cannot learn if they are disrespected, demeaned, or diminished.

A sharing circle format can be used to encourage a sense of collective learning and nurture relationships (Baskin, 2005). In addition to providing participants with information about the historical and contemporary context of Indigenous cultural safety, facilitators also engage participants in "emotional" learning activities that are intended to elicit identification and empathy. In fact, facilitators claim that, in this context, a shift in behaviour requires emotional experiences.

Facilitators talked about how they plant the seeds of cultural safety within individuals that will hopefully be nurtured within classrooms, curricula, departments, and disciplines. Role modeling plays an important part in this process, particularly in terms of creating safe spaces and respectfully engaging with others. This emphasis on relationality encourages participants of ICST to view themselves as part of a collective, to acknowledge their privilege, and to take responsibility for their behaviour. In other words, participants are being prepared to see each other as kin (as family) through the time and effort given to protecting, maintaining, and Journal of Contemporary Issues in Education, 2021, 16(2), pp. 55-83. 
sustaining relationships with each other, as well as being sensitive to complexities that exist (K. Anderson, 2020; Tilley, 2016).

For many staff, faculty, and leaders, ICST might be the first time they have engaged in sharing circle work, and the impact can be transformative. Yet, like most resourced programs, universities require evidence of the impact of ICST. This means that facilitators must document what they do, and completion rates are one sign of a positive outcome. There are, however, dimensions of this work that are difficult to quantify. As well, facilitators emphasized that knowing what people do with the training is as important as measuring what they have learned. For these reasons, the development of a tool to manage, measure, and report the impact of ICST was seen as having great value.

\section{Challenges of ICST}

The third theme relates to the challenges of ICST in terms of participants' readiness and subsequent safety, organizational supports, and the impact of ICST on facilitators.

\section{Participants' readiness and positions}

According to participants, peoples' initial attitudes about ICST has a substantial impact not only on the outcome but also on the process. Although highly recommended, some attend because they are interested in learning more about the history of Indigenous Peoples, while for others it is it an opportunity to improve on the strategies related to equity, inclusion, diversity, and decolonization. For most, the training can elicit feelings of embarrassment, shame, anger, and/or defensiveness. However, for those who have not engaged willingly, these feelings are much more difficult to process or put into perspective. Moreover, everyone enters the training environment with a unique identity, knowledge foundation, and understanding of the issues that is predicated on intersecting forms of privilege and oppression. This makes the role of facilitation very challenging in terms of ensuring that all participants get what they need from the training. The question of ICST participants' post-training status also emerged in discussions about when a person becomes "culturally safe" or is considered an ally. The consensus was that taking a 90-minute session or even a 2-day workshop was not sufficient to reach an adequate level of cultural safety. Indeed, Indigenous cultural safety does not occur as a result of one-time or short-term training but is a lifelong journey of self-reflection and learning. Further, the moniker of "ally" should not be taken on by an individual but rather be bestowed by others upon a person who consistently demonstrates solidarity and cultural safety (Swiftwolfe, 2018). This was particularly important in how non-Indigenous participants who participated in the sharing circle shared their own experiences of seeing culturally unsafe practices. More importantly, the ability of non-Indigenous participants to be totally present and committed to listening with respect, compassion and kindness to Indigenous perspectives about culturally safe and/or unsafe experiences was considered more important than proclaiming one's self as any "ally."

\section{Organizational supports}

Participants recognized the challenges that institutions can create by failing to adequately support ICST and/or culturally safe environments. In fact, institutional change was identified as the foundation of culturally-safe environments and includes, but is not limited to, policies, resources, curriculum and programs, Indigenous representation, and Indigenous community engagement. Participants also noted the development of Indigenous Plans, Indigenous faculty and student Journal of Contemporary Issues in Education, 2021, 16(2), pp. 55-83. 
welcoming ceremonies, and university-wide observance of Orange Shirt Day as examples of institutions moving beyond lip-service to create culturally-safe environments. Participants also stressed that when institutions make cultural safety count (e.g. through merit, promotion, incentives), ICST will become an integral part of academic and resource planning as well as curriculum development and pedagogy.

\section{Impact of ICST on facilitators}

Participants stressed that facilitating ICST is culturally and emotionally taxing work, requiring them to contend with participants' emotional responses as well as problematic participant interactions. In particular, unlike their non-Indigenous colleagues, in describing Indigenous-focused racism and discrimination, Indigenous facilitators often shared some of their most painful experiences. The vast majority of facilitators must also learn on the job how to deal with racist and/or aggressive participant responses, which can be equally traumatizing for facilitators who are Indigenous. These emotional consequences clearly affect the sustainability of this type of work; however, institutions rarely provide training or adequately compensate facilitators. In pursuit of self-care, facilitators often resort to commiserating with other facilitators and/or seeking the council of Elders or professional therapists.

\section{Culturally safe and inclusive pedagogy}

The fundamental impact of ICST was seen as creating culturally safe and inclusive interpersonal relationships, classroom settings, curriculum development, and policy-making (institutionally and structurally). For an ICST impact assessment tool to be effective, having the time to selfreflect and engage in personal and professional conversations about engagement, teaching, and learning with Indigenous students emerged as key considerations. The recommendation for prepost intervention measures aligns closely with the literature on behavioural change theory first conceptualised by Icek Ajzen (1985). Behavioural change theory was considered initially to measure an individual's actions (i.e. what is the desired behaviour we want to see changed as a result of the training?), targets (i.e. what will staff, faculty and leaders do to support their ongoing cultural safety development over time?), and context (i.e. where and when do staff, faculty and leaders employ culturally safe practices?). In the case of ICST, training must also include opportunities for staff, faculty, and leaders to fully integrate what they learn into their everyday professional and personal practice by adopting a more relational and inclusive teaching and learning process. Throughout the on-going workshops we identified and agreed upon four key culture of care values (i.e., awareness, respect, trust, and belonging) that align with "being a good relative." The culture of care values also helped to qualify the impact of the training as well as what those who completed the training say they are doing to develop culturally safe and inclusive work practices. Measuring the impact of the training and in particular describing the culture of care values required a shift in our thinking towards identifying the key ICST influences as items, categories, variables, statements, or potential questions. In addition, qualifying the four culture of care values as variables not only aligned with previously conducted reviews looking at the impact of experiences of discrimination in population health research pertaining to racism and health (Krieger et al., 2005), though perhaps more importantly, there is no single method that can grasp the subtle variations in ongoing human experience (Derrida, 1981). Therefore, values translated as variables can co-exist (quantiatively and qualitatively) as a human measure and/or qualifier to providing a deeper understanding about the Journal of Contemporary Issues in Education, 2021, 16(2), pp. 55-83. 
training, as well as people's intentions and behaviours related to how the training supports being culturally safe.

Full-day workshop

In addition, a full-day workshop was organized to discuss and refine the items, categories, and questions that emerged from the initial half-day workshops. The following questions, which emerged from the full-day workshop, further guided the development of the proposed ICST impact assessment tool, and included:

1. What are some of the ICST participants' concerns, fears, intentions, or expectations prior to doing the ICST?

2. Do the ICST participants intentions mirror or complement participants initial reactions immediately after having completed the training - personally and professionally? Positively, negatively, or no direct impact?

3. What impact has the ICST had on participants' planning (i.e. curriculum, leadership, policies, and/or spaces they work in), relationships (being a good relative) and interactions (i.e. empathetic, respectful, kind, and trustworthy) with Indigenous Peoples (i.e. students, Elders and community) 6-months later? Positively, negatively, or no direct impact?

4. What impact has the ICST had on participants' planning (i.e. curriculum, leadership, policies and/or spaces they work in), relationships (being a good relative) and interactions (i.e. empathetic, respectful, kind and trustworthy) with Indigenous Peoples (i.e. students, Elders and community) 12-months later? Positively, negatively, or no direct impact?

Working from these questions, and taking into consideration the four agreed upon pre-post time measures from the initial workshops (T1, T2, T3, \& T4), a set of more in-depth personal and professional practice variables, statements, and questions both qualitative (QS) and quantitative (Q) emerged. The use of tides as a culturally-appropriate and inclusive metaphor to articulate a shift in human behavioural change was proposed by Dr. Skip Dick (personal communication, July $18^{\text {th }}, 2019$ ) and based on the teachings of Coast Salish people's connection to the waters surrounding Vancouver Island (see Figure 5). The initial ICST impact assessment survey tool was framed using the following tides, and included:

1. Between the Tides: T1 (Pre): Self-Location and Awareness (Intentions).

2. Tides of Discovery: T2 (Immediately After - Post): Confidence and Capability (Initial Reactions).

3. Tides of Transition: T3 (Post-Post - 3-6 months): Reflection and Application (Actions Behaviours).

4. Tides of Confluence: T4 (Post-Post - 6-12 months): Opportunities and Commitment (Maintain-Expand).

However, what was expressed at our ICST workshops meetings is that implementation of the post-post part of the survey will vary depending on the length of the ICST in each institution. For example, ICST that was $2 \mathrm{hrs}$ in length versus ICST over a year effectively means that the timing of the post-post impact assessment survey tool may need to be adjusted accordingly. Holistically Journal of Contemporary Issues in Education, 2021, 16(2), pp. 55-83. (c) Author(s), Creative Commons Attribution 4.0 (CC BY 4.0) licence 
and relationally, the four Indigenous culturally mediated values (i.e. physical, mental, emotional, and spiritual) seek to address the whole person in terms of what they do, think, feel, see, and learn as "Being a Good Relative" (see Figures 5 \& 6). Although, important in respecting the whole person's health and wellbeing, all collaborators agreed that the core values should also reflect a more relational and inclusive learning journey; rather than seeing the training as merely a didactic exercise of telling people what they have to do to be culturally safe.

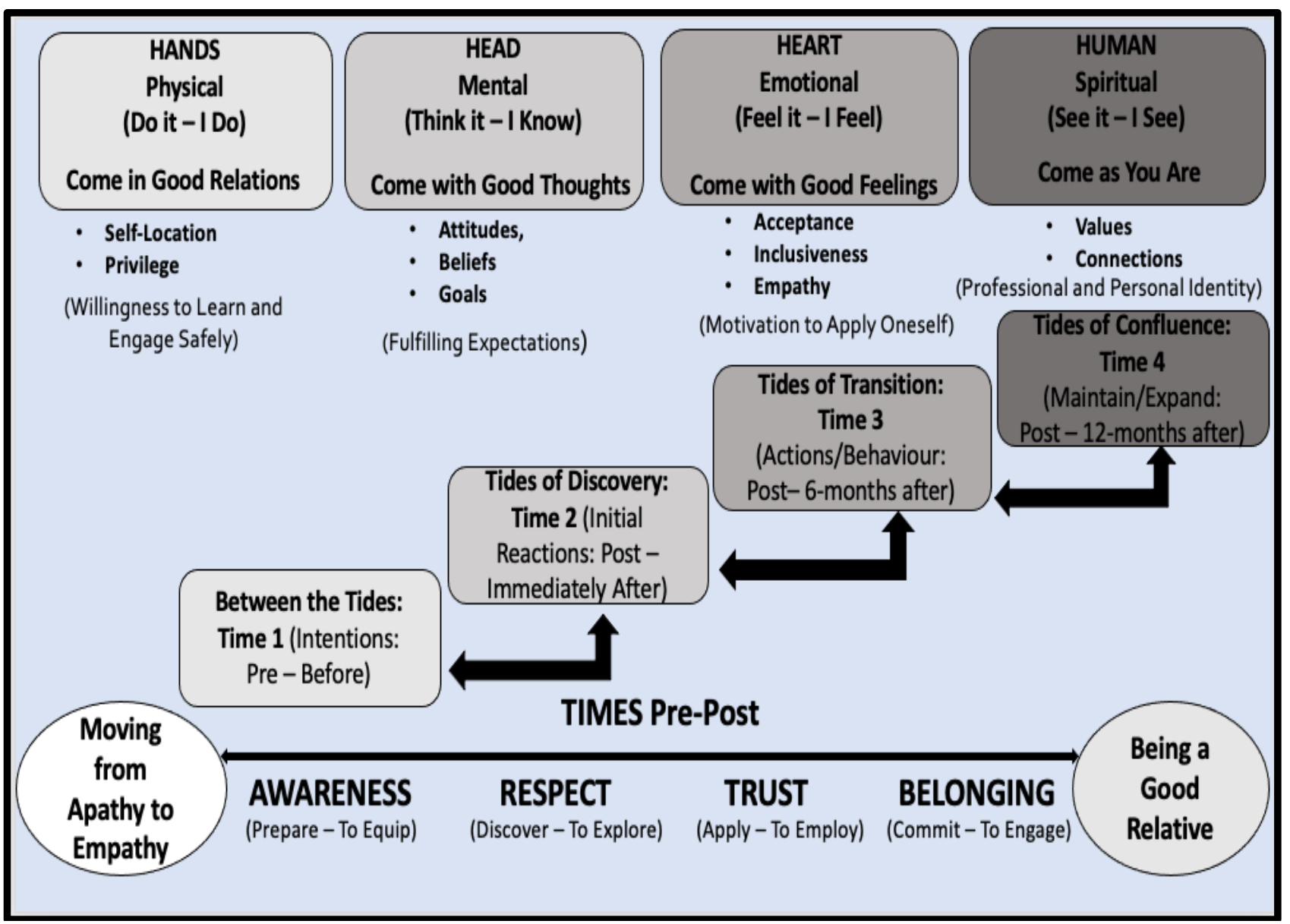

Figure 5: Being a Good Relative: Moving from Apathy to Empathy 


\begin{tabular}{|c|c|c|c|c|}
\hline 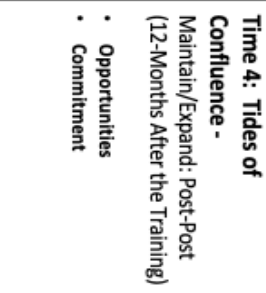 & 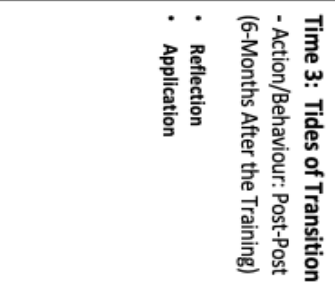 & 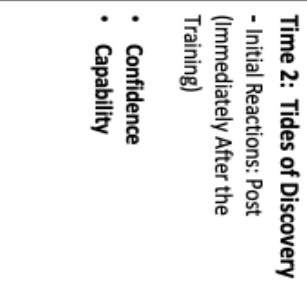 & 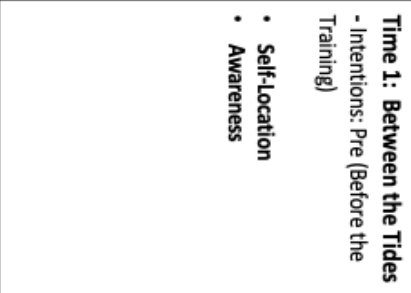 & 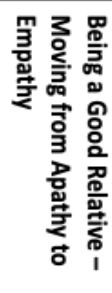 \\
\hline 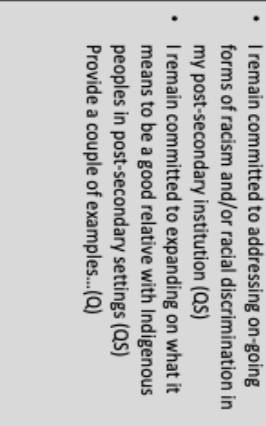 & 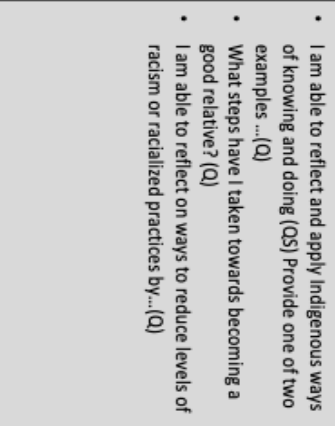 & 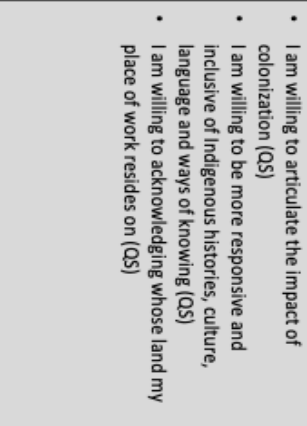 & 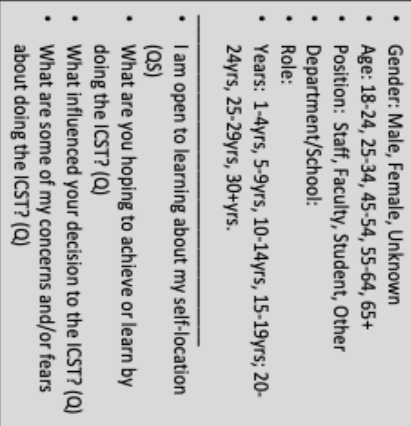 & 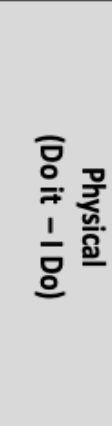 \\
\hline 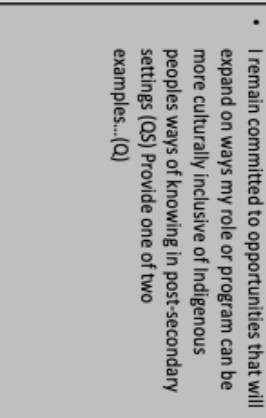 & 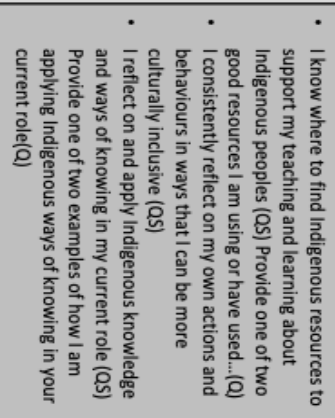 & 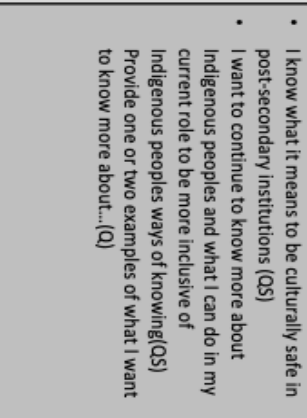 & 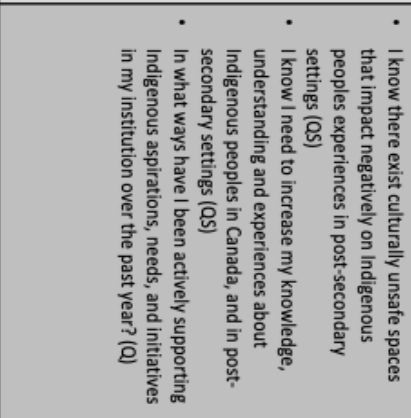 & 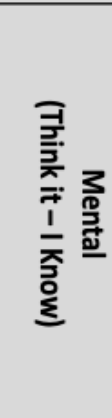 \\
\hline 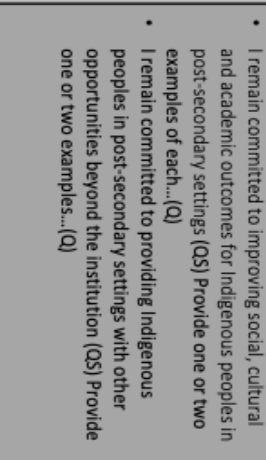 & 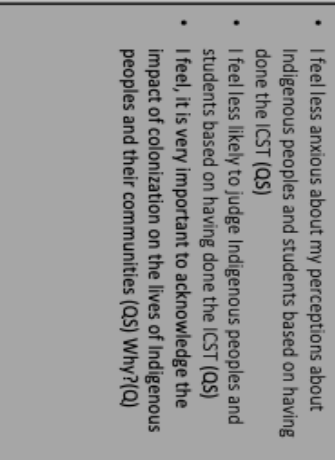 & 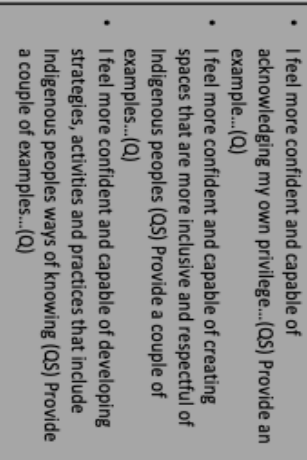 & 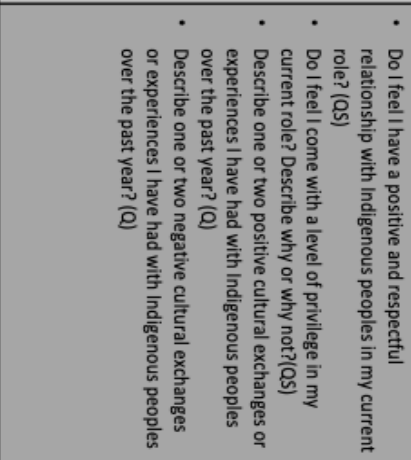 & 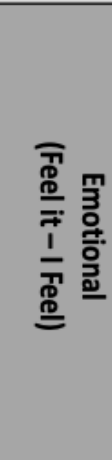 \\
\hline 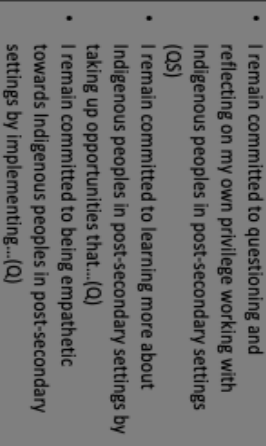 & 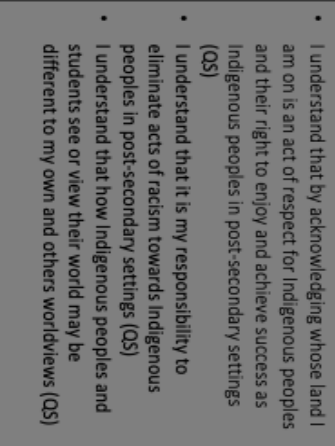 & 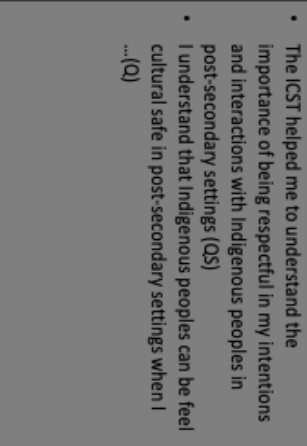 & 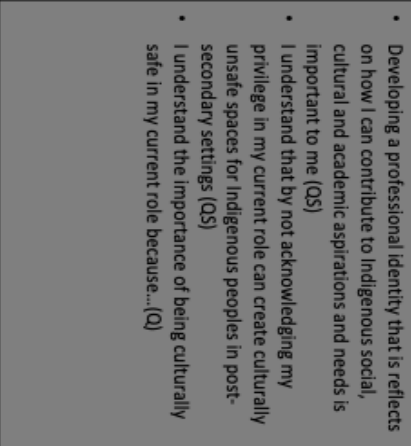 & 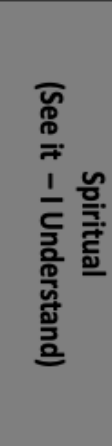 \\
\hline
\end{tabular}

Journal of Contemporary Issues in Education, 2021, 16(2), pp. 55-83. 
Figure 6: Proposed ICST Impact Assessment Survey Tool Items, Variables, Categories, Statements and Questions

As a result, the following culture of care variables: awareness, respect, trust, and belonging (Figure 7) emerged from a number of follow-up meetings with our collaborators who participated in a consensus-building exercise that helped to further refine the initial items, categories, variables, statements, and questions above (Figures $5 \& 6$ ) in a culturally-reasoned way.

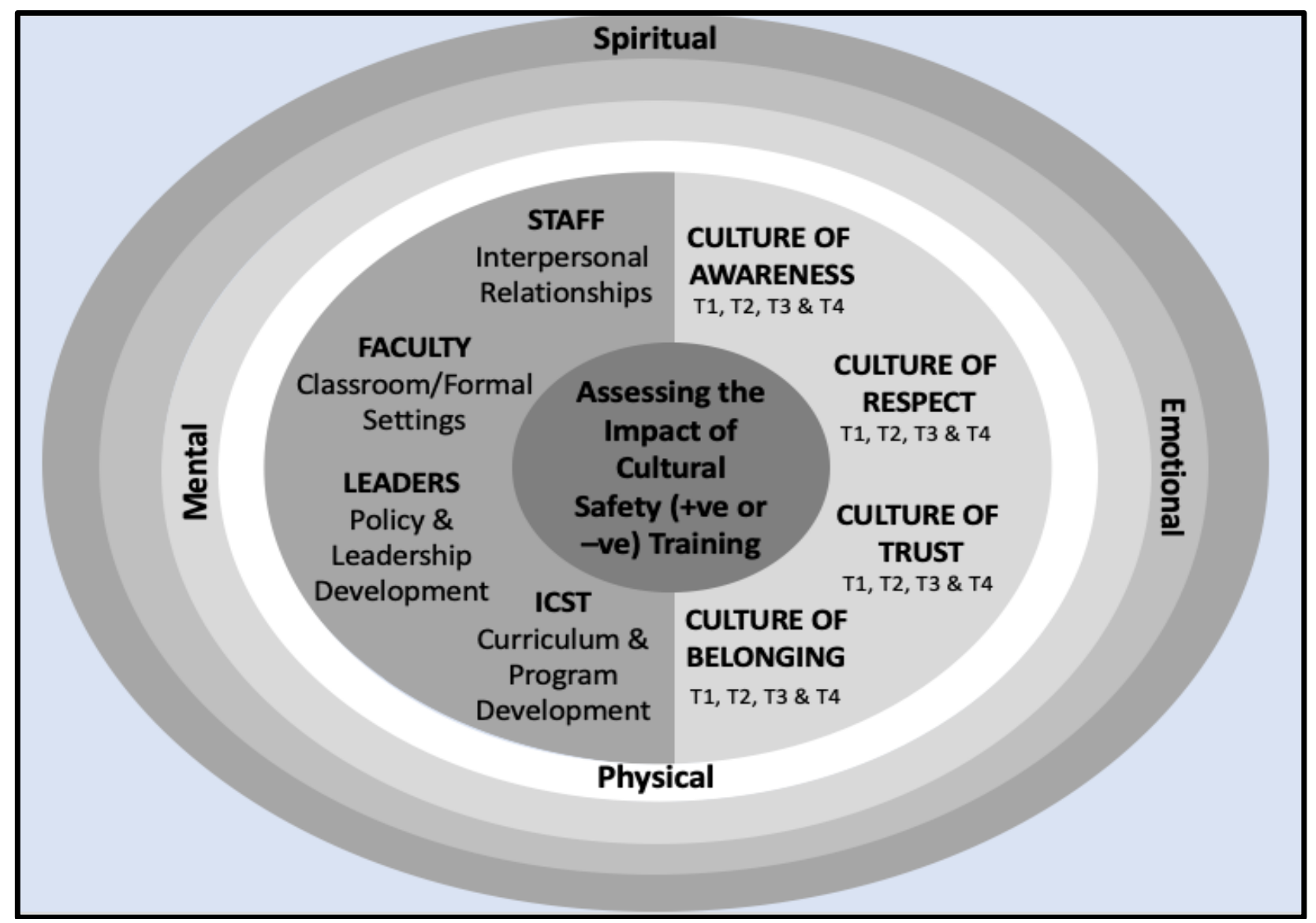

Figure 7: Impact Variables for Assessing the Impact of Cultural Safety Training for Staff, Faculty and Leaders in Post-Secondary Settings

\section{Culture of care impact variables}

A summary of the culture of care impact variables will further help support and guide ICST facilitators to use the impact assessment survey tool more effectively. The following four variable descriptions to emerge included:

\section{Awareness}

The variable of "awareness" centres around ICST participants' understanding of their own selflocation (i.e. the power and privilege that accompany their professional role and personal 
identity), as well as the impact that colonial policies and practices have on the lives of Indigenous Peoples. What do participants know, and how do they know what they know?

In the awareness stage, the ICST Assessment tool evaluates participants' cultural awareness, which involves attitudes that acknowledge differences between cultures (Koptie, 2009). Additionally, participants are empowered with knowledge through an understanding of their own cultural values, beliefs, attitudes, and outlooks that consciously or unconsciously affect their relationships with people (Ball, 2009; Papps \& Ramsden, 1996; Ramsden \& Spoonley, 1994). According to Curtis et al., cultural awareness is "a beginning step towards understanding that there is a difference," including "an individual's awareness of his/her own views such as ethnocentric, biased and prejudiced beliefs towards other cultures," as well as "recognizing that there are differences between cultures" $(2019$, p. 4). Awareness encompasses the beginning stages of cultural awareness through movement towards critical consciousness, involving critical self-reflection (Curtis et al., 2019, p. 4).

\section{Respect}

The "respect" variable captures relational shifts in ICST participants' feelings, attitudes, and beliefs towards Indigenous Peoples, as well as recognition of their own roles in the work of creating culturally safe spaces. Are participants showing openness and acknowledgment of different ways of seeing the world? Do they feel a sense of empathy and compassion towards Indigenous People? This stage of the cultural safety learning journey is about cultural sensitivity where participants "start to analyse their own realities and the impact that this may have on others" (Curtis et al., 2019, p. 4). This step "alerts students to the legitimacy of difference and begins a process of self-exploration as the powerful bearers of their own life experience and realities of the impact this may have on others" (p. 4). Respect statements attempt to measure the participants ability to critically self-reflect on the impact their views and prejudices have on others within a relational context.

\section{Trust}

The variable of "trust" centres around ICST participants' perceived abilities and intentional efforts to behave and act in culturally safe ways. What are participants doing differently in their personal and professional practice, based on what they know now? Are they confident in translating empathy into action? This is where the ICST Assessment Tool measures the development of cultural competency, across "a set of congruent behaviours, attitudes, and policies that come together in a system, agency, or among professionals and enable that system, agency, or those professionals to work effectively in cross-cultural situations" (Curtis et al, 2019, p. 29). This is where the participant starts to contribute towards a culturally competent culture within an institution in which, "the mutual and reciprocal learning, enabled by and through communities of practice, creates opportunities to engage in group critical reflexive practice and can aid in creating a culture of trust and connection, which is fundamental to enlist allies in the drive for change and transformation" (Pecci et al., 2020, p. 68).

\section{Belonging}

The variable of "belonging" relates to whether ICST participants have developed a sense of responsibility and accountability to ensure the safety, support, and success of Indigenous students and colleagues within the institution. Do participants indicate a sustained commitment Journal of Contemporary Issues in Education, 2021, 16(2), pp. 55-83. 
to thinking, being, and acting in culturally safe ways that include (rather than exclude)

Indigenous Peoples in their current roles? Similar to cultural humility, the culture of care "belonging" impact variable builds on the previous skills to include a commitment "to selfevaluation and self-critique" and to "having an interpersonal stance that is other-oriented rather than self-focused, characterized by respect and lack of superiority toward an individual's cultural background and experience" (Curtis et al., 2019, p. 4-5). Participants understand this "does not have an endpoint or goal...but [is] an active process, an ongoing way of being in the work and being in relationships with others and self" (Curtis et al., 2019, p. 4-5).

The tool will not only assess the impact and efficacy of the training, but it will also support staff, faculty, and leaders to better self-evaluate their own interpersonal relationships, classroom settings, policy and leadership development, and curriculum program, working with Indigenous students in these settings with the option of using the following scales to help measure and/or qualify various statements and questions used within the impact assessment survey tool (Figure 8): Always (+2), Mostly (+1), Sometimes (0), Rarely (-1), or Not Yet (-2); or, Strongly Agree $(+2)$, Agree (+1), Sometimes Agree (0), Disagree (-1), or Strongly Disagree (-2).

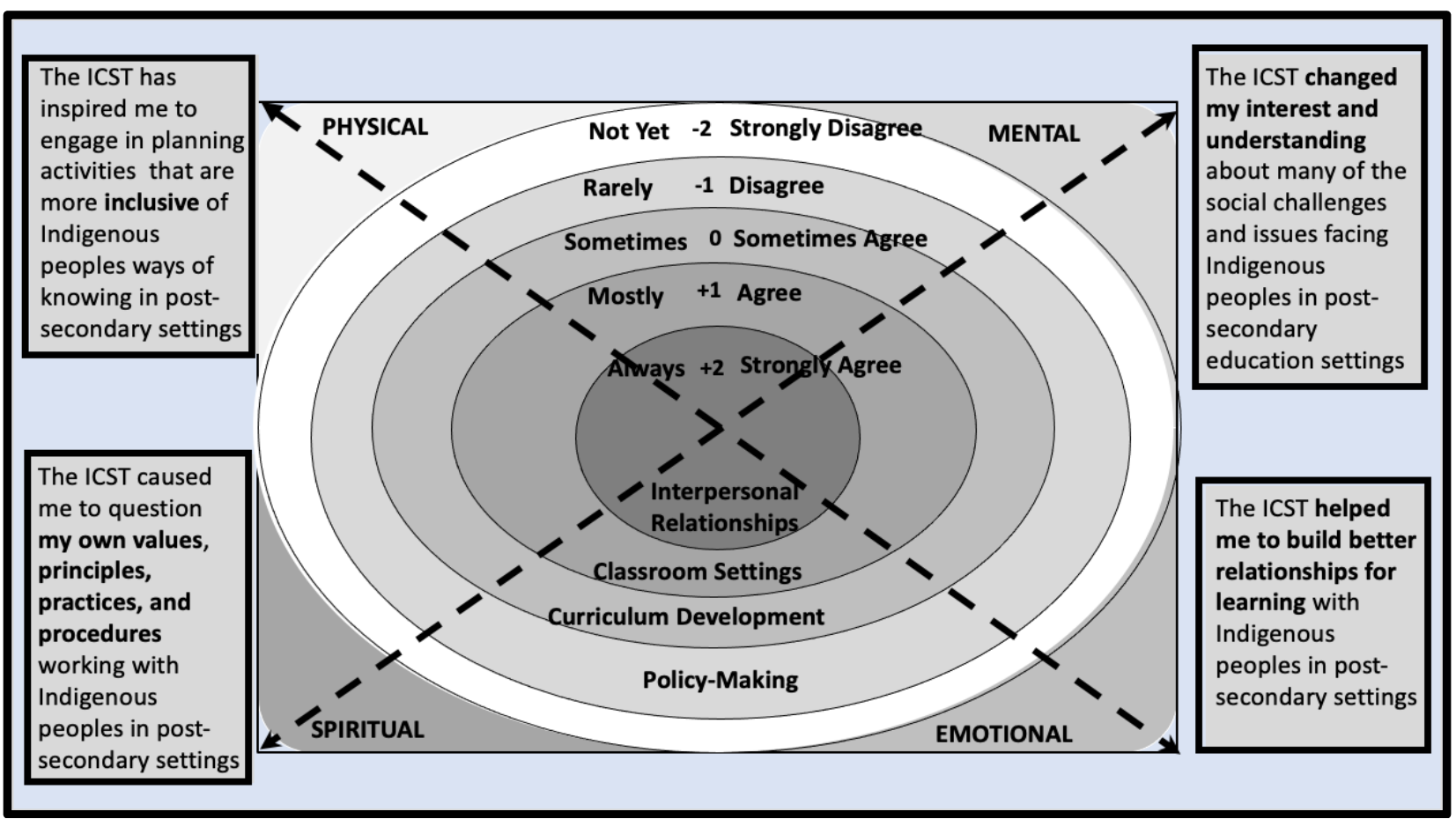

Figure 8: ICST Participant Self-Evaluation Learning Outcomes

Similarly, the following learning outcomes could be adapted and included as part of the selfevaluation process shared above (Figure 8) and work in parallel to further improve the ICST offered in these settings. Based on the level of feedback we received from the ICST workshops and meetings, developing a set of guidelines (as opposed to standards) for faculties, departments, schools, and workplaces in post-secondary to work towards were preferred. 


\section{Level 1:}

- WE ensure that our teaching, learning, and work practices are tailored to the needs and aspirations of Indigenous students and reflect their communities' world view, values, practices, and principles;

- WE listen and work together with Indigenous students and their communities to mutually decide what types of programs, courses, and models of learning delivery and support services are appropriate;

- OUR school, department, faculty, and institution acknowledge and engage respectfully within a range of Indigenous settings, realities, and contexts across a number of different contexts, programs, and courses we teach.

\section{Level 2:}

- WE engage with Indigenous students and their communities consistently, as early as possible, and when there is the potential for the greatest educational gains and opportunities to build positive relationships;

- WE explore a range of Indigenous models, interventions, assessments, and practices that are informed by wise or evidence-based research;

- WE are committed to co-working or partnering with people who have skills working with Indigenous students (e.g. Elders, First People's House, and Indigenous staff, faculty and leaders).

\section{Level 3:}

- WE work collaboratively with other schools, colleges, agencies, authorities, organizations, and Indigenous communities to provide comprehensive teaching, learning, and social-cultural supports that benefit Indigenous students;

- WE commit to continuously improving our skills and competencies as a team working with Indigenous students;

- WE are continuously reviewing opportunities and our capabilities to provide more effective programs, courses, and spaces for Indigenous students to thrive and be successful with/in their learning, as well as to feel supported within the institution;

- WE can demonstrate that Indigenous models, interventions, assessments, and practices form a core part of our team's work in order to achieve better outcomes for Indigenous students and their communities.

\section{Next Steps}

\section{Validation process}

Participants from the half-day and full-day ICST workshops were asked to participate in one of 
the two half-day workshops provided to help validate and further refine the impact assessment survey tool. In this project, it was important to employ a consensus decision-making process that is akin to ways Indigenous Peoples prioritise and make decisions as a collective. (Shotton et al., 2017). The first group (ICST content experts and ICST facilitators) will examine, discuss and refine the survey items and corresponding personal and professional practice variables over two, half-day sessions. The second group (individuals who have previously completed ICST) will be invited to participate in an individual "think-a-loud" sessions where they will be asked to narrate their thought-process as they complete a draft of our current impact assessment survey tool. Previous studies have demonstrated that ongoing verbalization during task performance is an effective way to verify whether questions elicit the kinds of interpretation and responses intended (Trenor et al. 2011). Together, both groups will provide valuable feedback that can be further triangulated with the First Peoples Principles of Learning (First Nations Education Steering Committee, 2014), TRC: Calls to Action (Truth and Reconciliation Commission, 2015), and UNDRIP (United Nations General Assembly, 2007) to further refine the ICST impact assessment survey tool.

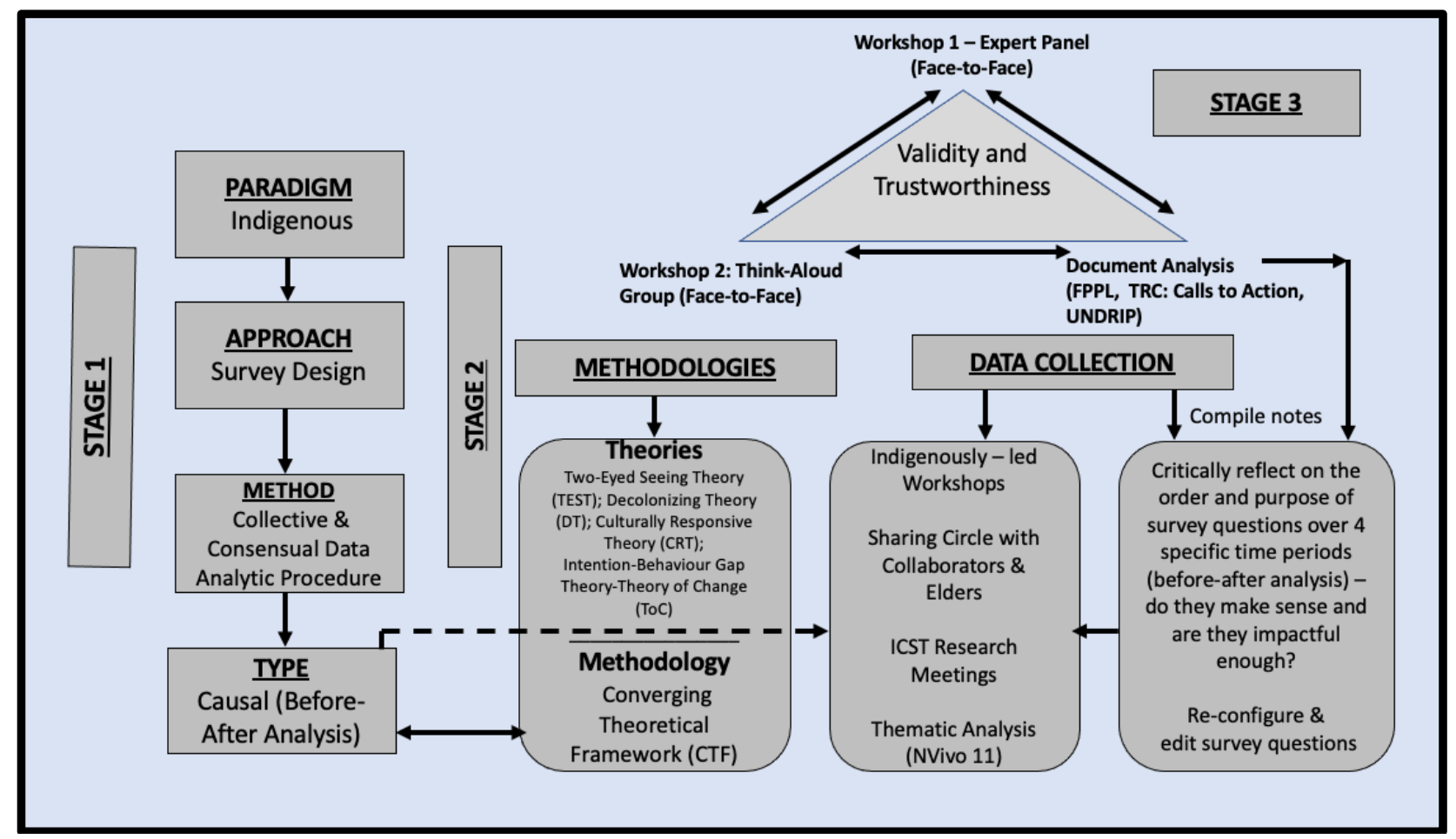

Figure 9: Research Design Road Map

Although, the process of validating survey tools is a common practice among researchers seeking to ensure the questions, items, and statements developed are purposeful, relevant, and free of ambiguity, Shotton et al. (2017) contend,

[w]e grapple with questions of what are dominant forms of validity practices and what additional layers of validity are added when viewing research through an Indigenous lens. We argue that an Indigenous form of validity is relational. Our connections with each 
other are to think through, conceptualize with, and validate our research, which adds to, or reframes, the traditional colonized roles of researcher and participants. (p. 637)

Therefore, the validation sessions were informed by aspects of Bartlett's Collective Consensual Data Analytic Procedure (CCDAP) (Bartlett et al., 2007) and the Intention-Behaviour Gap Theory that aligns with the Theory of Change (ToC) (Figure 9). The CCDAP was first conceptualized and applied in Bartlett and colleagues' (2007) Aboriginal-guided decolonizing health research study involving Metis and First Nations persons with diabetes. In practice, consensus decision-making on emergent themes from the data is achieved collectively (rather than by the researcher in isolation) through open-ended questions and in-depth discussions conducted "in a manner that minimizes the intrusion of terms that may culturally and contextually lack cogency with First Nations and Metis populations" (p. 2377). CCDAP not only ensures the appropriate crediting of Indigenous knowledge but also facilitates "reciprocal capacity building" and "bi-directional discovery" among Indigenous and non-Indigenous research participants - two attributes recognized as essential to decolonizing research (Bartlett et al. 2007, pp. 2378-2379). Others who have adapted the CCDAP model recognize it as filling a "methodological niche" for a data analysis method that "satisfies the needs of Indigenous world views," particularly in addressing a need for "building relationships, mutual respect, facilitating reciprocal information sharing, and ensuring research findings are relevant" (Starblanket et al. 2019, pp. 3, 9).

While the CCDAP underpins how we intend to conduct the validation workshops in a culturally conscious and ethical way, the ToC will also guide us in checking our process for "accountability and internal awareness of potential organizational challenges" in creating culturally safe spaces (Dembek et al., 2017, p. 16-17). Critical to the ToC framework is the ability to clearly identify our project's vision, mission, and goals, and to "work backwards" in order to elucidate any underlying assumptions that, if left unchecked, could lead to unintended negative consequences, outcomes, or setbacks.

Without a standardized and effective way of measuring the long-term impact of ICST we cannot be certain that the training is doing what it is intended to do - which is not simply to diversify spaces (i.e. filling diversity quotas) but to make these spaces culturally-safe and inclusive for Indigenous Peoples coming to the institution from culturally "diverse backgrounds" (Goldstein Hode, et al., 2018). This means moving staff, faculty, and leaders in post-secondary institutions towards non-discriminatory and anti-racist behaviours, while promoting cultural equity and inclusion so that Indigenous students have every opportunity to thrive and succeed in these settings.

\section{Conclusion}

The goal of this research project was to develop an impact assessment survey tool to assess the effectiveness of ICST in post-secondary education settings. In this article, we described the context and methods with which the research was undertaken; highlighted the research questions, goals, and purpose underpinning ways to measure the impact and efficacy of the training; and provided feedback about ways for staff, faculty and leaders to better self-evaluate the impact of the training on their own practice. Improving one's interpersonal relationships, classroom Journal of Contemporary Issues in Education, 2021, 16(2), pp. 55-83. (c) Author(s), Creative Commons Attribution 4.0 (CC BY 4.0) licence http:/lejournals.library.ualberta.ca/index.php/JCIE 
settings, curriculum development, and leadership practices were highlighted as potential areas for personal and professional self-improvement. The proposed self-evaluation process (Figure 8) also provides staff, faculty, and leaders ways to self-reflect and find ways to further improve their personal and professional practice post-ICST. After completing the validation portion of this project, the ICST impact assessment survey tool will be piloted with participants who have completed ICST at the University of Victoria and Royal Rhodes University in Victoria, BC to gain valuable feedback, and to further refine the tool.

From its conception, and now in its final stages of completion, the project was not only Indigenous-led, it was also rooted in a convergence approach that drew upon the relational values, principles, and strengths of both Indigenous and non-Indigenous reasoned ways of knowing. In addition, the development of culturally strong and authentic research relationships were pivotal at every step of the research process. Not only does the tool highlight the potential to better inform the design and implementation of ICST programs in post-secondary settings across Canada, it also has the ability to improve the relevance of Indigenous ways of knowing in how we can assess other forms of cultural training in areas such as tourism, health, sport, recreation, leisure, business, and beyond. In essence, the project and the future pilot testing of the impact assessment survey tool, promises to reshape the organizational and institutional working culture in ways that aim to address more coherently the TRC: Calls to Action (2015), UNDRIP (2007), First Peoples Principles of Learning (2014) including other equity, inclusion, and diversity initiatives working to benefit Indigenous Peoples in these spaces. Finally, it is hoped that this project will continue to build on the on-going discussions (nationally and internationally) related to the roles and responsibilities of post-secondary institutions have to provide culturally-safe and inclusive environments that see Indigenous Peoples enjoying and achieving educational success as Indigenous Peoples (Ministry of Education, 2008). In this regard, we believe the project has the potential to make a significant contribution to furthering ICST assessment and development in British Columbia, and beyond.

\section{References}

Absolon, K. (2011). Kaandossiwin: How we come to know. Fernwood Publishing.

Ajzen, I. (1985). From intentions to actions: A theory of planned behavior. In J. Kuhl \& J. Beckman (Eds.), Action control: from cognition to behavior (pp. 11-39). Springer. https://doi.org/10.1007/978-3-642-69746-3_2

Anderson, J., Perry, J., Blue, C., Browne, A., Henderson, A., Khan, K. B., ... Smye, V. (2003). Rewriting cultural safety within the postcolonial and postnational feminist project. Advances in Nursing Science, 26(3), 196-214.

Anderson, K. (2020). On Seasons of an Indigenous feminism, kinship, and the program of home management. Hypatia, 35(1), 204-213. https://doi.org/10.1017/hyp.2019.10

Ball, J. (2009). Cultural safety in health care for Aboriginal Peoples [Presentation]. British Columbia Public Health Services Authority \& Vancouver Coastal Health Authority. Vancouver, BC, Canada. http://www.ecdip.org/docs/pdf/Cultural safety in health care compr.pdf

Ball, J., Moselle, K., \& Moselle, S. (2013). Contributions of culture and language in Aboriginal Head Start in urban and northern communities to children's health outcomes: A review of theory and research. http://cahr.uvic.ca/nearbc/media/docs/cahr51f0ade9a51cf-phac- 
ashunc-language-and-culture-report.pdf

Bartlett, J.G., Iwasaki, Y., Gottlieb, B., Hall, D., \& Mannell, R. (2007). Framework for Aboriginal-guided decolonizing research involving Métis and First Nations persons with diabetes. Social Science \& Medicine, 65(11), 2371-2382. https://doi.org/10.1016/j.socscimed.2007.06.011

Baskin, C. (2005). Storytelling circles: Reflections of Aboriginal protocols in research. Canadian Social Work Review, 22(2), 171-187.

Battiste, M. (2004). Discourses of difference; cognitive imperialism; culturalism and diversity. https://www.google.ca/search?q=Discourses+of+difference;+cognitive+imperialism;+cul turalism + and + diversity.\&ie $=$ utf- $8 \&$ oe $=$ utf8\&gws_rd=cr\&ei=jxZjV5DZONfEjwPO8Y2oCg

Battiste, M. (2015). Nurturing the learning spirting of the Indigenous learner [Keynote]. WINHEC-WIRA Symposium (August 12-13 ${ }^{\text {th }}$ ). Seven Generations Education Insitute, Nanicost, Fort Frances, Ontario, Canada.

Boyce, J. (2016). Juristat - victimization of Indigenous peoples in Canada, 2014. Statistics Canada.

Brooks-Cleator L., Phillipps, B., \& Giles, A. (2018). Culturally safe health initiatives for Indigenous Peoples in Canada: A scoping review. Canadian Journal of Nursing Research, 50(4), 202-213. https://doi.org/10.1177\%2F0844562118770334

Churchill, M., Parent-Bergeron, M., Smylie, J., Ward, C., Fridkin, A., Smylie, D., \& Firestone, M. (2017). Evidence brief: Wise practices for Indigenous-specific cultural safety training programs. Well Living House Action Research Centre for Indigenous Infant, Child and Family Health and Wellbeing, and Centre for Research on Inner City Health, St. Michael's Hospital, Toronto, Ontario, Canada.

Cross, T.L., Bazron, B. J., Dennis, K.W., \& Issacs, M.R. (1989). Towards a culturally competent system of care. National Technical Assistance Centre for Children's Mental Health \& Georgetown University Child Development Centre.

Curtis, E., Jones, R., Loring, B., Paine, S., Reid, P., Tipene-Leach, D., \& Walker, C. (2019). Why cultural safety rather than cultural competency is required to achieve health equity: A literature review and recommended definition. International Journal for Equity in Health, 18(1), 1-17. https://doi.org/10.1186/s12939-019-1082-3

Datta, R. (2017). Decolonizing both researcher and research and its effectiveness in Indigenous research. Research Ethics, 14(2), 1-24. https://doi.org/10.1177/1747016117733296

Dembek, K., York, J., Dodd, R., Rodriguez, L., \& Sheth, U. (2017). Actionable impact management: A framework for social impact strategy, measurement, \& demonstration. Asia Pacific Social Impact Centre, Melbourne Business School.

Derrida, J. (1981). Positions. University of Chicago Press.

Dhillon, S. S. (2010). In SEARCH of GOD: The God of spirituality. Lulu Enterprises Incorporated.

Environics Institute. (2010). Urban Aboriginal Peoples study: Background and summary of main findings. Retrieved from https://www.uaps.ca/wpcontent/uploads/2010/02/UAPS_Summary_Final.pdf

Erb, T. L. (2020). Facilitating Indigenous cultural safety and anti-racism training: Affect and the emergence of new relationships and social change [Unpublished master's thesis].

University of Victoria. Retrieved from https://dspace.library.uvic.ca/handle/1828/11697

First Nations Education Steering Committee. (2014). Poster: First Peoples principles of

Journal of Contemporary Issues in Education, 2021, 16(2), pp. 55-83. 
learning. Retrieved from http://www.fnesc.ca/first-peoples-principles-of-learning/

Gerlach, A.J. (2012). A critical refection on the concept of cultural safety. Canadian Journal of Occupational Therapy, 79, 151-158. https://doi.org/10.2182/cjot.2012.79.3.4

Goldstein Hode, M., Behm-Morawitz, E., \& Hays, A. (2018). Testing the effectiveness of an online diversity course for faculty and staff. Journal of Diversity in Higher Education, 11(3), 347-365. https://doi.org/10.1037/dhe0000063

Health Council of Canada. (2012). Empathy, dignity, and respect: Creating cultural safety for Aboriginal people in urban health care. Health Council of Canada. https://healthcouncilcanada.ca/437/

Javidan, M., \& House, R.J. (2001). Cultural acumen for the global manager: Lessons from Project GLOBE. Organizational Dynamics, 29(4), 289-305. https://doi.org/10.1016/S0090-2616(01)00034-1

Koptie, S. (2009). Irihapeti Ramsden: The public narrative on cultural safety. First Peoples Child and Family Review, 4(2), 30-43.

Kirkham, S.R., Smye, V., Tang, S., Anderson, J., Blue, C., Browne, A., ... Shapera, L. (2002). Rethinking cultural safety while waiting to do fieldwork: Methodological implications for nursing research. Research in Nursing \& Health, 25.

Krieger, N., Smith, K., Naishadham, D., Hartman, C., \& Barbeau, E.M. (2005). Experiences of discrimination: Validity and reliability of a self-report measure for population health research on racism and health. Social Science \& Medicine, 61(7), 1576-1596. https://doi.org/10.1016/j.socscimed.2005.03.006

Ladson-Billings, G. (2009). The dreamkeepers: Successful teachers of African American children. Wiley.

Lenette, C. (2014). Teaching cultural diversity in first year human services and social work: The impetus for embedding a cultural safety framework. A practice report. The International Journal of the First Year in Higher Education, 5(1), 117-123.

Loppie, C., \& Wien, F. (2009). Health inequalities and social determinants of Aboriginal Peoples' health. National Collaborating Centre for Aboriginal Health.

Macfarlane, A.H., Blampied, N.M., \& Macfarlane, S. (2011). Blending the clinical and the cultural: A framework for conducting formal psychological assessment in bicultural settings. New Zealand Journal of Psychology, 40(2), 5-15.

MacIntyre, G. (2016). Cross-cultural awareness and sensitivity training in the communications management and recruitment and retention of international students at Atlantic Canadian universities [Unpublished master's thesis]. Mount Saint Vincent University.

Marshall, A. (2005). The science of humility. Te Toi Roa - Indigenous Excllence: World Indigenous Peoples' Conference on Education (Novermber 27-December 1, 2005), Hamilton, New Zealand. Retrieved from https://pdffox.com/the-science-of-humilityalbert-marshall-pdf-free.html

Marshall, A., \& Bartlett, C. (2010). Two-eyed seeing \& integrated science - an old-new way of bringing together different perspectives. Institute for Integrated Science \& Health. Retrieved from http://www.integrativescience.ca/Articles/

Marshall, M., Marshall, A., \& Bartlett, C. (2015). Two-eyed seeing in medicine. In M. Greenwood, S. de Leeuw, N.M. Lindsay, \& C. Reading (Eds.), Determinants of Indigenous peoples' health in Canada: Beyond the social (pp. 16-24). Canadian Scholars' Press. 
Ministry of Education. (2008). Ka Hikitia - managing for success: Māori educational strategy 2008-2012. Ministry of Education, Wellington, New Zealand.

Moussaïd, M., Kämmer, J.E., Analytis, P. P., \& Neth, H. (2013). Social influence and the collective dynamics of opinion formation. PLOS ONE, 8(11), e78433. https://doi.org/10.1371/journal.pone.0078433

National Center for Culturally Responsive Educational Systems (NNRESt). (2008). Module 5: Culturally responsive literacy. Academy 1: Literacy for what? Facilitator's manual. Arizona State University, Tempe, Arizona.

Papps, E., \& Ramsden, I. (1996). Cultural safety in nursing: The New Zealand experience. International Journal of Quality in Health Care, 8(5), 491-497.

Pecci. A., Frawley, J., \& Nguyen, T. (2020). On the critical, morally driven, selfreflective agents of change and transformation: A literature review on culturally competent leadership in higher education. In J. Frawley, G. Russell, \& J. Sherwood (Eds.), Cultural Competence and the Higher Education Sector (pp. 59-81). Springer. https://doi.org/10.1007/978-981-15-5362-2_5

Provincial Health Services Authority. (2016). British Columbia San'yas Indigenous cultural safety training. http://www.sanyas.ca/training/british-columbia

Public Health Agency of Canada. (2018). Key health inequalities in Canada: a national portrait. https://www.canada.ca/content/dam/phac-aspc/documents/services/publications/scienceresearch/key-health-inequalities-canada-national-portrait-executive-summary/hirexecutive-summary-eng.pdf

Ramsden, I. (1990). Kawa whakaruruhau: cultural safety in nursing education in Aotearoa. Minstry of Education, Wellington, New Zealand. Retrieved from http://www.moh.govt.nz/NoteBook/nbbooks.nsf/0/707224BC1D4953C14C2565D70019 0AD9?opendocument

Ramsden, I. (2002). Cultural safety and nursing in education in Aotearoa [Unpublished doctoral dissertation]. Victoria University. Retrieved from https://mro.massey.ac.nz/bitstream/handle/10179/2411/02_whole.pdf

Ramsden, I., \& Spoonley, P. (1994). The cultural safety debate in nursing education in Aotearoa. New Zealand Annual Review of Education, 3, 161-174.

Reading, C. (2013). Understanding racism. Retrieved from http://www.nccahccnsa.ca/Publications/Lists/Publications/Attachments/103/understanding_racism_EN_we b.pdf

Rhodes, R.E., \& Yao, C.A. (2015). Models accounting for intention-behavior discordance in the physical activity domain: A user's guide, content overview, and review of current evidence. International Journal of Behavioral Nutrition and Physical Activity, 12(1), 114. https://doi.org/10.1186/s12966-015-0168-6

Saskamoose, J., Bellegarde, T., Sutherland, W., Pete, S., \& McKay-McNabb, K. (2017). Miýopimātisiwin developing Indigenous cultural responsiveness theory (ICRT): Improving Indigenous health and well-being. International Indigenous Policy Journal, 8(4). https://doi.org/10.18584/iipj.2017.8.4.1

Shotton, H.J., Tachine, A.R., Nelson, C.A., Minthorn, R.Z., \& Waterman, S.J. (2017). Living our research through Indigenous scholar sisterhood practices. Qualitative Inquiry, 24(9), 636-645. https://doi.org/10.1177/1077800417744578

Smith, D.E. (2005). Institutional ethnography: A sociology for people. AltaMira Press. 
Smith, G.H. (2014). Transforming research - the emerging Indigenous research context in Aotearoa - New Zealand [Jean Herbison lecture]. AARE-NZARE Conference, Brisbane, Australia. Retrieved from http://www.nzare.org.nz/herbison-lecture.aspx

Smith, L.T. (2012). Decolonizing methodologies: Research and Indigenous peoples. Otago University Press.

Starblanket, D., Lefebvre, S., Legare, M., Billan, J., Akan, N., Goodpipe, E., \& Bourassa, C. (2019). Nanâtawihowin Âcimowina Kika-Môsahkinikêhk Papiskîci-Itascikêwin Astâcikowina [Medicine/healing stories picked, sorted, stored]: Adapting the collective consensual data analytic procedure (CCDAP) as an Indigenous research method. International Journal of Qualitative Methods, 18, 1609406919896140. https://doi.org/10.1177/1609406919896140

Swiftwolfe, D. (2018). Indigenous ally toolkit. Retrieved from https://physiotherapy.ca/sites/default/files/indigenous_ally toolkit_en.pdf

Thomas, R., \& Green, J. (2007). A way of life: Indigenous perspectives on anti-oppressive living. First Peoples Child \& Family Review, 3(1), 91-104.

Tilley, S.A. (2016). Doing respectful research: Power, privilege and passion. Fernwood Publishing.

Torchiano, M., Fernández, D., Travassos, G., \& de Mello, R. (2017). Lessons learnt in conducting survey research. Proceedings of the 2017 IEEE/ACM 5th International Workshop on Conducting Empirical Studies in Industry (CESI), 33-39. https://doi.org/10.1109/CESI.2017.5

Trenor, J.M., Miller, M.K., \& Gipson, K.G. (2011). Utilization of a think-aloud protocol to cognitively validate a survey instrument identifying social capital resources of engineering undergraduates [Conference presentation]. 2011 ASEE Annual Conference \& Exposition, Vancouver, BC.

Truth and Reconciliation Commission of Canada. (2015). Truth and reconciliation commission of Canada: Calls to action. Retrieved from https://www2.gov.bc.ca/assets/gov/britishcolumbians-our-governments/indigenous-people/aboriginal-peoplesdocuments/calls_to_action_english2.pdf

Tuck, E., \& Yang, K.W. (2012). Decolonization is not a metaphor. Decolonization: Indigeneity, Education and Society, 1(1), 1-40. Retrieved from http://decolonization.org/index.php/des/article/view/18630

United Nations General Assembly. (2007). United Nations declaration on the rights of Indigenous peoples. http://www.iwgia.org/iwgia_files_publications_files/UNDRIP.pdf

Universities Canada. (2015). Universities Canada principles on Indigenous education. Retrieved from http://www.univcan.ca/wp-content/uploads/2015/11/principles-on-indigenouseducation-universities-canada-june-2015.pdf

Warren, J., \& Weatherford, J. (2013). Pilot study: The impact of a brief motivational interviewing training class on a measure of participant's empathy. VISTAS Online, (17), 1-12. Retrieved from https://www.counseling.org/knowledge-center/vistas/bysubject2/vistas-assessment/docs/default-source/vistas/pilot-study---the-impact-of-a-briefmotivational-interviewing-training-on-a-measure-of-participants-empathy 